\title{
A EDUCAÇÃO ESCOLAR RURAL NO ESTADO DE SÃO PAULO ENTRE 1890 E 1970: BREVE DISCUSSÃO SOBRE O RURALISMO PEDAGÓGICO
}

\author{
Jaqueline Daniela Basso \\ UFSCar \\ Luiz Bezerra Neto ${ }^{2}$ \\ UFSCar/FAPESP
}

\section{RESUMO}

Este trabalho surge a partir de uma pesquisa realizada como parte da dissertação sobre as escolas no campo e as salas multisseriadas no Estado de São Paulo, apresentada ao Programa de Pós-Graduação em Educação da Universidade Federal de São Carlos e de outra sobre concepção de educação e ensino rural no Estado de São Paulo, com apoio da FAPESP. Pretendemos neste trabalho realizar uma discussão acerca da educação escolar rural no Estado de São Paulo entre os anos de 1890, (período em que aconteceu a primeira reforma educacional republicana neste Estado), e a década de 1970, momento em que a industrialização desviava as atenções governamentais do meio rural para as cidades. Assim, buscaremos discutir o processo histórico de expansão da educação escolar, sobretudo no campo, bem como a influência do ruralismo pedagógico neste processo.

Palavras- chave: escolas rurais; Estado de São Paulo; Ruralismo Pedagógico

\section{RURAL EDUCATION IN THE STATE OF SÃO PAULO BETWEEN 1890 AND 1970: A BRIEF DISCUSSION ON RURALISM PEDAGOGICAL}

\begin{abstract}
This work comes from a survey conducted as part of dissertation on schools in the field and the multi-year classes in the State of São Paulo, presented to the Graduate Program in Education at the Federal University of São Carlos and the other about design education and rural education in the State of São Paulo, with the support of FAPESP. We intend to make this work a discussion of rural school education in the State of São Paulo between 1890 (the period in which happened the first Republican education reform in this state), and the 1970s, when the industrialization diverted government attention the rural areas to the cities. Thus, we will seek to discuss the historical process of expansion of school education, especially in rural areas, as well as the influence of rurality this educational process. Keywords: schools in the country; São Paulo; Ruralism Pedagogical
\end{abstract}

Este trabalho surge a partir de uma pesquisa realizada como parte da dissertação sobre as escolas no campo e as salas multisseriadas no Estado de São Paulo apresentada ao Programa de Pós-Graduação em Educação da Universidade Federal de São Carlos e de outra sobre concepção de educação e ensino rural no Estado de São Paulo, com apoio da FAPESP. Aqui pretendemos realizar um recorte histórico acerca da educação escolar no campo no Estado de São Paulo entre os anos de 1890, em que aconteceu a primeira reforma educacional republicana neste Estado, e a década de 1970, em que a industrialização desviava as atenções governamentais do meio rural para as cidades. 
Muito se tem dito sobre a precariedade das escolas rurais e suas desvantagens materiais em relação às escolas das cidades desde fins da década de 1980, entretanto, este não é um fenômeno recente, desta maneira, buscaremos discutir neste trabalho de que modo a educação escolar se expandiu no Estado de São Paulo e as possíveis causas da denunciada carência material nas escolas no campo.

Estas denúncias são feitas por estudiosos como Kolling, Néry e Molina (1999, p. 45), representantes do "Movimento por Uma Educação do Campo", surgido em 1997, que trouxe em seu cerne a influência dos movimentos sociais do campo, representados, principalmente, pelo Movimento dos Trabalhadores Rurais Sem Terra. Estes autores afirmam que a educação no campo sempre foi tratada como resíduo do sistema educacional presente nas cidades, desta maneira, a escola no campo tem enfrentado problemas como: falta de infraestrutura adequada e qualificação docente; ausência de apoio e renovação pedagógica; currículos e calendários inadequados às necessidades do campo; atuação de docentes com visão de mundo urbana ou agrícola patronal; distanciamento das necessidades e interesses daqueles que vivem e trabalham no campo, sobretudo os trabalhadores rurais assalariados e assentados da reforma agrária.

De acordo com os defensores do movimento "por uma educação do campo", isto faz com que as escolas ali situadas, muitas vezes, trabalhem contra si, estimulando o abandono dos trabalhadores deste meio. Esta situação se daria pelo fato dos professores apresentarem a cidade como superior ao campo, moderna e atraente, colaborando para o deslocamento dos estudantes para as cidades (KOLLING, NÉRY E MOLINA, 1999, p. 45). Embora tais constatações sejam importantes para o debate sobre a educação do campo, não podemos esquecer que refletem a concepção de que o campo difere da cidade, e por isso necessita de uma educação específica. Esta questão merece estudos mais detalhados para que possamos compreender em que circunstâncias históricas se originaram as denunciadas más condições da educação no campo.

Para tanto, é necessário que se compreenda que o Estado de São Paulo foi pioneiro na tentativa de construção de um sistema de ensino, surgido logo após a Proclamação da República em 1889 e consequente instauração do regime federativo. A partir daquele momento a instrução popular foi mantida a cargo das províncias, transformadas em Estados, como ocorrera desde 1834. Contudo, já em 1890 foi instituída por Benjamin Constant a reforma dos ensinos primário e secundário, que mesmo limitada ao Distrito Federal serviria de modelo para os demais Estados. De acordo com Saviani,

a tentativa mais avançada em direção a um sistema orgânico de educação foi aquela que se deu no estado de São Paulo. Ali procurou preencher dois requisitos básicos implicados na organização dos serviços educacionais na forma de sistema: a) a organização administrativa e pedagógica do sistema como um todo, o que implica a criação de órgãos centrais e intermediários de formulação das diretrizes e normas pedagógicas bem como de inspeção, controle e coordenação das atividades educativas; b) a organização das escolas na forma de grupos escolares, superando por esse meio, a fase das cadeiras e classes isoladas, o que implicava a dosagem e graduação dos conteúdos distribuídos por séries anuais e trabalhados por um corpo relativamente amplo de professores que se encarregavam do ensino de grande número de alunos, emergindo, assim, a questão da coordenação destas atividades também no âmbito das atividades escolares. Ora, a reforma da instrução pública paulista, implementada entre 1892 e 1896, pioneira na organização do ensino primário na forma de grupos escolares, procurou preencher os dois requisitos apontados (SAVIANI, 2008, p. 165). 
A partir do modelo empreendido no Distrito Federal, o Estado de São Paulo pretendia organizar sua educação por meio de órgãos centralizados e normas que direcionariam a educação de todo o Estado. Os grupos escolares, constituem-se assim, em um marco de pioneirismo visando diminuir quando não fosse possível, acabar com as escolas isoladas, que em sua maioria eram unidocentes, ou seja, se resumiam a turmas onde um único professor instruía alunos em diversos níveis de aprendizagem ao mesmo tempo, assim, os grupos escolares se transformaram em escolas graduadas, portanto, separadas em séries que agrupavam alunos com conhecimentos semelhantes.

Para Zeila de Brito Fabri Demartini, a reforma era necessária pois, "o sistema de ensino paulista, até a proclamação, era profundamente insatisfatório, em termos quantitativos e qualitativos" (DEMARTINI, 1989, p. 6). Contudo, a reforma paulista não se concretizou naquele momento em que as oligarquias cafeeiras passaram a gerenciar o regime republicano. Foi necessário aguardar o período final da República Velha, com a crise dos anos 1920, para que as reformas da instrução pública nos Estados fossem retomadas e o problema do sistema de ensino passasse a ser tratado em âmbito nacional após a Revolução de 1930 (SAVIANI, 2008, p. 166). Embora tenha ocorrido um movimento em direção à reforma do ensino paulista no período da República Velha, que levaria à uma sistematização e modernização do ensino, por meio da instituição dos grupos escolares, o poder oligárquico cafeeiro, impôs sua centralidade, impedindo assim que a reforma se concretizasse.

Saviani (2008, p. 166-167) afirma que o sistema de ensino, enquanto ideia pedagógica implica sua realização prática, portanto, sua materialização. Desta maneira, o sistema nacional de ensino foi idealizado no século XIX enquanto forma organizacional prática da educação, e se materializaria em uma ampla rede de escolas que englobassem todo o território nacional, que articular-se-iam entre si, por meio de normas e objetivos comuns. Sua implementação exigia condições materiais preliminares, dependentes de grande investimento financeiro, daí talvez resulte a não concretização do sistema nacional de ensino neste período, dada as condições materiais precárias, advindas do financiamento insuficiente da educação. Para Saviani,

as dificuldades para a realização da ideia de sistema nacional de ensino se manifestaram tanto no plano das condições materiais como no âmbito da mentalidade pedagógica. Assim, o caminho da implantação dos respectivos sistemas nacionais de ensino, por meio do qual os principais países do Ocidente lograram universalizar o ensino fundamental e erradicar o analfabetismo, não foi trilhado pelo Brasil. $\mathrm{E}$ as consequências desse fato projetam-se ainda hoje, deixando-nos um legado, de agudas deficiências no que se refere ao atendimento das necessidades educacionais do conjunto da população (SAVIANI, 2008, p. 168).

A discussão realizada por Saviani nos faz perceber que o investimento insuficiente na educação é histórico no Brasil. Vemos que desde fins do século XIX, a falta de recursos financeiros no sistema nacional de educação vem prejudicando o desenvolvimento da escolarização brasileira, que se encontra atrasada em relação a outros países ocidentais.

O pouco investimento na educação no século XIX gerou consequências, visto que, durante boa parte do século XX, a carência de vagas e a inexistência de escolas para atendimento de toda a demanda, ainda desafiaram o avanço da obrigatoriedade escolar e dos ideais de democratização do acesso à escola, mesmo com a expansão gradual do ensino primário, financiado pelo governo estadual. Assim, 
o acesso em quantidade restrita atingiu grupos sociais distintos, privilegiando moradores da zona urbana em detrimento da zona rural, e, nas cidades, assistindo setores diferenciados da população, especialmente a classe média, entre as camadas populares, os trabalhadores mais bem situados na estrutura econômica e social eram os privilegiados (SOUZA, 2009, p. 117).

Percebemos então, que o acesso dos habitantes das cidades à educação também não era uniforme, ela se destinava a integrantes da classe média e trabalhadores com melhores condições materiais, ou seja, a dita "democratização" do acesso ao ensino primário não se destinou inicialmente a todos, mas aqueles que possuíam condições materiais para frequentarem as poucas escolas disponíveis.

Zeila de Brito Fabri Demartini reitera essa discussão afirmando que,

se os ideais republicanos eram amplos e dirigidos a toda a população, a política educacional adotada durante este período foi de atendimento restrito e preferencial às populações urbanas, em detrimento das populações residentes em áreas rurais, que eram consideradas na época, como as mais avessas à educação escolar [...] deixavam-se os setores considerados mais arredios sempre para momentos posteriores, ou recebendo uma educação diferenciada e inferior à que se propunha para as áreas urbanas (embora residisse na zona rural, neste período, a maior parte da população paulista) (DEMARTINI, 1989, p. 6).

O que evidencia que a questão da oferta de educação escolar não era direcionada pelo local onde as pessoas viviam, mas ao processo de divisão do trabalho uma vez que, ela alcançava àqueles que dela necessitavam para se integrar ao processo laboral. Assim, os trabalhadores rurais, cuja mão de obra era pouco diferenciada, não eram prioridade nos investimentos em educação escolar pública.

No período da Primeira Guerra Mundial (1914 - 1917), a educação popular ${ }^{3}$ ganhou importância nos debates públicos sobre os rumos da sociedade brasileira, sendo novamente considerada como a solução para os problemas nacionais. O nacionalismo era o terreno fértil para as mobilizações em torno dos problemas do país.

Se no plano político a oligarquia era culpabilizada pelo desvirtuamento da República, no plano social, a organização do trabalho e a manutenção da ordem eram problemas imperiosos para os quais se voltavam às elites econômicas, os políticos e os intelectuais. A construção da nação passava pela reforma moral e intelectual do povo brasileiro, o que implicava empreender esforços no sentido de reconstruir a ordem social ameaçada pelas greves e movimentos operários, nacionalizar o imigrante e educar as massas, pois, o analfabetismo constituía o grande mal que aniquilava o país (SOUZA, 2009, 117-118).

Naquele período, a educação era vista como possibilidade de redenção social visto que, existiam "problemas" sociais que precisavam ser solucionados, e a solução perpassava pela educação, que não estava diretamente relacionada à disseminação dos conhecimentos historicamente construídos, mas à um projeto de disciplinamento tanto do povo brasileiro quanto dos imigrantes, visando impedir que eles se unissem e assim representassem uma ameaça à ordem capitalista nacional. De acordo com Demartini,

O colono imigrante foi a solução econômica encontrada para a agricultura paulista, mas constituía, ao mesmo tempo, um "perigo nacional", do 
ponto de vista político. E, nesse caso, a escola era vista por muitos como uma forma de atenuar este perigo. Mas, mesmo nestes casos em que a criação de escolas era considerada problema urgente e fundamental, sua implantação nem sempre realmente se efetivava. Um exemplo é o que ocorreu com as 30 escolas criadas pela Lei de 16 de dezembro de 1909: foram alocadas e providas somente duas. Desse modo, as preocupações permaneciam, em muitos casos, teóricas (DEMARTINI, 1999, p. 8).

Demartini nos mostra que havia um discurso em favor da educação no período da primeira república, porém, estava em jogo questões políticas como aculturação dos imigrantes que faziam com que muitas vezes o discurso suplantasse as ações em busca da solução do real problema da educação naquele período, o alto índice de analfabetismo.

Em 1918, Oscar Thompson, então diretor geral da instrução pública em São Paulo, levantou a questão das deficiências na disseminação da educação popular no Estado. Em 1920, ao assumir a Diretoria Geral da Instrução Pública, Sampaio Dória, com o apoio do governador, Washington Luiz, colocou em ação uma das mais polêmicas reformas educacionais empreendidas no Estado de São Paulo e no Brasil no início do século XX, visando o fim do analfabetismo infantil (SOUZA, 2009, p. 118-119).

Visando reduzir os índices de analfabetismo, realizou-se uma profunda reorganização do ensino público, que abalou as bases do sistema escolar paulista que haviam se solidificado no início do período republicano. Dentre as principais ações da Reforma de 1920 estavam, a redução do ensino primário para dois anos, tanto em escolas urbanas quanto rurais; criação de um ensino médio que compreendia os antigos terceiro e quarto anos do primário; redução da obrigatoriedade da frequência e gratuidade da escola primária, ficando obrigadas a frequentarem as escolas as crianças de nove e dez anos; a taxação do curso médio e o desdobramento do turno de funcionamento das escolas isoladas (ANTUNHA, 1976, p. 162-163).

Desta maneira, mesmo o Estado de São Paulo sendo pioneiro na busca por reformas que melhorassem a qualidade e o acesso à educação primária, nos anos de 1920 o Estado ainda se deparava com altos índices de analfabetismo. A saída para esta situação foi a proposição de uma reforma na educação, que priorizasse a aquisição das primeiras letras. Porém, mesmo servindo à fins autênticos, os métodos propostos por esta reforma foram bastante criticados, devido a seu desajuste em relação à política de disseminação dos grupos escolares que vinha sendo empreendida desde o início do período republicano.

A Reforma educacional de 1920 vinha na contramão dos princípios educativos até então defendidos, por reduzir a duração do primário, transformando dois de seus quatro anos no curso médio, por propor medidas que reduziriam o déficit da educação, pois a redução da obrigatoriedade e gratuidade do ensino primário, que agora se direcionava à crianças de nove e dez anos e a taxação do curso médio, automaticamente diminuiriam a demanda de alunos e reduziriam os gastos do governo estadual com a educação. Outro ponto que se aclara é a possibilidade da iniciativa privada se apropriar da instrução primária no Estado devido à redução da gratuidade. Contudo, acreditamos que, a medida que mais incomodou os críticos à reforma, foi o desdobramento do período das escolas isoladas, visto que, se opunha ao desejo de disseminar os grupos escolares, tidos como modelos da educação moderna, em todo o Estado de São Paulo.

Além das críticas sofridas no interior do Estado, a Reforma do Ensino paulista ainda sofreu outras fora dele, o que impulsionou o debate fervoroso, na década de 1920, sobre os rumos da educação brasileira, isto é, sobre os caminhos que seriam traçados para se alcançar um projeto de modernização da educação, que, colaborasse para a reforma da sociedade. Nesta mesma década, Sampaio Dória dirigiu um detalhado recenseamento 
escolar, que tornou ainda mais evidente o problema do analfabetismo infantil paulista. Para Souza,

a maior parte da população concentrava-se na zona rural, nas vilas e bairros. Por isso, na opinião de Sampaio Dória, o problema das escolas isoladas configurava-se o mais urgente a ser enfrentado, particularmente no que dizia respeito à moradia do professor e à sala de aula [...] Sampaio Dória expunha assim, problemas crônicos do ensino primário na zona rural: a falta de casa para a escola, a dependência do professor, o mandonismo político local e sua interferência na questão do ensino (SOUZA, 2009, p. 121).

Assim, nas duas primeiras décadas do século $\mathrm{XX}$, faltavam vagas nas escolas das cidades, porém, no campo os problemas se agravavam, passando pela ausência de um local que abrigasse a escola isolada, a dependência do docente que, não tinha moradia perto da escola e tinha que se deslocar da cidade, percorrendo grandes distâncias sem os meios de transportes existentes hoje, além do coronelismo, assim definido por José Murilo de Carvalho,

[...] o coronelismo é, então, um sistema político nacional, baseado em barganhas entre o governo e os coronéis. O governo estadual garante, para baixo, o poder do coronel sobre seus dependentes e seus rivais, sobretudo cedendo-lhe o controle dos cargos públicos, desde o delegado de polícia até a professora primária. O coronel hipoteca seu apoio ao governo, sobretudo na forma de votos. Para cima, os governadores dão seu apoio ao presidente da República em troca do reconhecimento deste de seu domínio no estado. O coronelismo é fase de processo mais longo de relacionamento entre os fazendeiros e o governo. O coronelismo não existiu antes dessa fase e não existe depois dela. Ele morreu simbolicamente quando se deu a prisão dos grandes coronéis baianos, em 1930. Foi definitivamente enterrado em 1937, em seguida à implantação do Estado Novo e à derrubada de Flores da Cunha, o último dos grandes caudilhos gaúchos (CARVALHO, 1997, s.p.).

O coronelismo era sentido na educação no campo no início do século XX, pois, em sua maioria, as escolas se localizavam dentro das fazendas, e com isto, estavam sob o domínio dos coronéis, que além do capital financeiro, detinham poder político, o que lhes dava condições de intervir na educação escolar.

No período em que vigorou a Reforma, entre 1920 e 1924, houve um incremento da matrícula geral e na frequência escolar, consequência de medidas administrativas que faziam valer a obrigatoriedade escolar, como a matrícula compulsória e aplicação de multas em prol da frequência. Desta forma, a política de ampliação das vagas incidiu mais sobre a expansão da rede escolar existente do que sobre a criação de novas escolas. Pela primeira vez, desde a reforma republicana de 1890, suspendeu-se a criação e instalação dos grupos escolares em detrimento da criação das escolas reunidas, que condensavam as escolas isoladas, que naquele período tiveram seu desenvolvimento desacelerado. Porém, com o fim da Reforma, em 1925, a antiga estrutura do ensino primário foi reerguida, tendo os cursos dos grupos escolares quatro anos de duração e os das escolas isoladas e reunidas, três. O grupo escolar novamente passou a ser prioridade na expansão da educação, com isto, muitas escolas reunidas foram transformadas em grupos e outras desmembradas em escolas isoladas (SOUZA, 2009, p. 122).

Fica evidente que durante o período da reforma houve um movimento em favor das escolas isoladas enquanto possibilidade de diminuição do analfabetismo, porém, com o fim 
da mesma, elas voltaram a ser condenadas, dando lugar aos grupos escolares. Outro fator que merece atenção é o de que quando a educação paulista retomou suas características, a educação que acontecia nas escolas isoladas e reunidas, que coincidia com a educação do campo, teve sua duração diminuída em comparação à das cidades. Revelando-se aí a diferenciação histórica e persistente entre a educação das urbes e aquela que acontece no campo. Assim,

em meados do século XX, a democratização do ensino público em São Paulo restringia-se à escolaridade primária nas zonas urbanas. Em relação aos outros níveis de ensino as oportunidades educacionais ainda eram menores [...] Em relação ao ensino primário, o desequilíbrio entre a demanda e a oferta de escolarização e a persistente diferenciação entre escola urbana e escola rural retratam as múltiplas formas pelas quais se processou a escolarização da infância. Essa diferenciação atesta também os entraves históricos de realização do ideal democrático de universalização de uma escola comum para todos (SOUZA, 2009, p. 124).

Ou seja, a separação entre a educação das cidades e do campo no Estado de São Paulo é um fenômeno que acontece desde o século XIX e prejudica o processo de universalização da educação no Estado, pois, campo e cidade, são partes da mesma totalidade social. É esta consciência que embasa nosso trabalho, quando falamos aqui em educação no campo, não estamos primando por uma educação diferenciada daquela que ocorre nas cidades, mas pelo acesso daqueles que vivem no campo à uma educação, com no mínimo, as mesmas condições existentes nas escolas das cidades, que lhes permita ter uma formação geral, no próprio meio em que vivem. Ou seja, procuramos aqui romper a diferenciação entre a educação urbana e a rural, considerando que, a educação deve ser comum a todos os indivíduos da sociedade, sejam eles da classe trabalhadora ou das camadas dominantes.

Para tanto nos embasamos em Gramsci que atenta para o fato de que a civilização moderna tende a criar uma escola para cada prática, em busca de dirigentes e especialistas,

assim, ao lado do tipo de escola que poderíamos chamar de "humanista" (e que é o tradicional mais antigo), destinado a desenvolver em cada indivíduo humano a cultura geral ainda indiferenciada, o poder de pensar e de saber se orientar na vida, foi-se criando paulatinamente todo um sistema de escolas particulares de diferente nível, para inteiros ramos profissionais ou para profissões já especializadas e indicadas mediante uma precisa especialização (GRAMSCI, 1968, p.117).

Gramsci embasa nossa crítica às educações específicas visto que, elas deixam de lado os conhecimentos que são realmente interessantes ao trabalho educativo, ou seja, aqueles que permitem aos homens exercerem sua condição humana. Assim, defender o respeito às diversas demandas existentes no campo seria considerar a possibilidade de termos uma educação exclusivamente indígena, outra voltada à cultura e fazeres das comunidades quilombolas, outra ainda que ensinasse apenas a trabalhar a terra, e tantas quantas possíveis, o que certamente, limitaria a oportunidade de aquisição da cultura geral.

Esta preocupação com as diferentes demandas educacionais é fruto da tendência atual de acabar com qualquer espécie de escola "desinteressada" e "formativa" para a classe trabalhadora, mantendo-as apenas para uma pequena elite, composta por aqueles que não precisam se preocupar com o preparo funcional. Em contrapartida, a grande massa popular tem seu futuro e destino profissional pré-definidos nas inúmeras escolas 
profissionais. Tal situação somente será revertida se houver uma "escola única inicial de cultura geral, humanista, formativa, que equilibre equânimemente o desenvolvimento da capacidade de trabalhar manualmente (tecnicamente, industrialmente) e o desenvolvimento das capacidades de trabalho intelectual" (GRAMSCI, 1968, p.118).

A formação baseada na cultura geral, que permite ao indivíduo aliar o trabalho material e intelectual certamente, faz com que os homens tenham capacidade de perceber que sua integração ao mercado de trabalho e condição de explorados não são acontecimentos naturais. Desta maneira, é a partir do conceito da Escola Única de Gramsci que nos posicionamos à favor de uma educação comum para o campo e a cidade.

Porém, vemos que, este não foi o caminho percorrido pela educação brasileira, tampouco paulista. Como já debatemos aqui, as escolas isoladas eram focos das mudanças na organização das escolas de primeiras letras paulistas do século XIX. Desta maneira, elas passaram a ocupar lugar secundário no sistema de ensino primário do Estado, sendo desprezadas pelo poder público e pelos docentes. No decorrer do século XX, embora ainda aparecessem nas cidades, em bairros populares, distritos, vilas industriais e concentrações de colonos, as escolas isoladas foram cada vez mais se tornando sinônimos da escola primária tipicamente rural (SOUZA, 2009, p. 148).

Portanto, as escolas isoladas já não mais serviam aos centros urbanos no século XIX, contudo continuavam aparecendo nas periferias das cidades e, sobretudo, no campo durante o século XX, comprovando que, historicamente, a educação que é oferecida aos trabalhadores é diferente daquela a que a elite tem acesso. E no campo isto se torna ainda mais evidente, dado que, como

unidades escolares modestas e simples, as escolas isoladas, localizadas em sua grande maioria na zona rural, caracterizam-se durante o século XX pela carência e abandono. Nessas escolas o curso primário tinha duração menor e programas mais simplificados. Os professores recebiam vencimentos menores que os dos grupos escolares. Faltavam casas próprias para o funcionamento das escolas. Os resultados do ensino eram poucos profícuos [...] Casas de tábuas, barracos, casebres e algumas edificações de alvenaria. A escola entre as plantações, o pátio de terra sem cobertura, algumas crianças descalças... Nessa ambiência do mundo rural, a cultura escrita assalta em contraponto (SOUZA, 2009, p. 149).

Esta descrição de Rosa Fátima de Souza é muito próxima daquela que fizemos sobre a educação no campo no início deste capítulo. Precariedade física, currículo empobrecido, má remuneração docente e consequente baixa qualidade na educação são constatações que acompanharam a educação no meio rural desde o século XIX e atravessaram o século $\mathrm{XX}$, o que leva a crer que a cultura letrada parece distante da realidade daqueles que tem a roça como seu local de trabalho e vida.

Esta situação é consequência do processo desigual de expansão do capital, da indústria e, consequentemente, do ensino primário no Estado de São Paulo, que no primeiro quinquênio do século $\mathrm{XX}$ favoreceu as áreas urbanas, mesmo com a maioria da população alocada no campo, situação semelhante ocorreu em outros Estados brasileiros, daí a constatação de que

É preciso ver nessa política educacional direcionada para o espaço urbano algo mais, além do atendimento da demanda. Outros fatores estiveram em jogo como as pressões políticas, a relação custo/ benefício considerando a aglomeração de crianças nas cidades, a visibilidade pública das ações do Estado e os interesses de modernização e de manutenção da ordem social. A difusão da educação no meio rural compreendia um investimento 
oneroso e de enfrentamento de inúmeros obstáculos de natureza econômica, política e social que os governos do estado de São Paulo não ousaram enfrentar (SOUZA, 2009, p. 149).

Aqui visualizamos a complexidade das influências que permearam a expansão da educação para o campo, embora houvesse demanda, uma vez que a maioria da população naquele período estava no campo. Havia questões políticas ligadas ao projeto de modernização do país, que estava mais próximo da indústria do que das atividades agropecuárias, além do próprio marketing político, pois, as ações do Estado nas cidades eram bem mais visíveis do que aquelas ocorridas no campo, portanto, tinham mais condições de fortalecer os governos que as empreendesse.

Além das questões puramente políticas, havia também os problemas orçamentários, dado que os governos alegavam que a educação no meio rural gerava altos custos. Outra demanda já levantada aqui, diz respeito a influência política e financeira dos coronéis, que naquele momento era bastante relevante, pois, geralmente as escolas isoladas eram instaladas em locais cedidos pelos coronéis no interior das fazendas, assim, eles acabavam ganhando autoridade em relação à educação que ali se realizava, o que acabava aparecendo como um obstáculo para o avanço da educação no campo.

Assim, no início do século XX, disseminou-se a representação de que a população rural não se interessava pela escola, o que foi muito útil tanto para o Estado, que assim justificava a inferioridade dos investimentos na educação rural, quanto para os docentes, que buscavam fugir da hostilidade do ambiente rural e das más condições de trabalho lá encontradas (SOUZA, 2009, p. 150).

Contudo, nas décadas de 1920 e 1930, muitos pensadores ruralistas buscaram evidenciar os problemas da educação rural, embasados em projetos mais abrangentes para a sociedade brasileira. Naquele período, diferentes projetos de modernização da sociedade estavam em jogo. De um lado, a modernização do país era representada pelas indústrias, e de outro, a economia agrária, já alicerçada nacionalmente aparecia como a melhor opção (SOUZA, 2009, p. 150).

Dentre os pedagogos ruralistas estava Sud Menucci, o mais conhecido do movimento no Estado de São Paulo. Estes educadores criticavam o modelo único de escola primária existente no Estado, por estar alicerçado nos valores e culturas urbanas, não serviria ao homem do campo, colaborando para o êxodo rural. Desta maneira, viam a criação da Escola Rural como uma forma de fixar o homem no campo (SOUZA, 2009, p. 150). Portanto, este grupo de intelectuais, pedagogos ou livre-pensadores, defendiam a existência de uma pedagogia que colaborasse com a fixação do homem no campo, ou então, dificultasse e até mesmo impedisse sua saída deste ambiente, considerado natural para os povos que nele habitam a muito tempo (BEZERRA NETO, 2003, p.11).

Essas propostas surgiram em um momento em que o Brasil passava por grandes transformações nos planos econômico e político. Em uma conjuntura marcada por mais uma crise cíclica do capitalismo, o início da década de 1930 foi caracterizado, no Brasil, por dificuldades econômicas e prejuízos para os proprietários de terras, produtores de gêneros agrícolas para exportação e, em especial, para a oligarquia cafeeira, sofrendo consequente enfraquecimento político. Naquelas circunstâncias, os setores mais conservadores, mesmo divididos, temendo a rearticulação de movimentos que propusessem mudanças radicais na política e na economia, tomaram a iniciativa de depor o presidente Washington Luiz (1926-1930) e conduziram Getúlio Vargas ao governo central, embora 
tivesse sido derrotado nas eleições presidenciais pelo paulista Júlio Prestes (BEZERRA NETO, 2003, p. 11-12).

Ou seja, os ideais ruralistas surgiram em um contexto diferente daquele do final do século XIX, em que a oligarquia cafeeira tinha força econômica e política para conter reformas educacionais. Em meio a uma crise capitalista, nos anos 1920, a elite agrária viu ir embora, junto com seus lucros, parte de seu o poder político.

Neste contexto, a educação rural paulista estava esquecida, desde a tentativa mal sucedida de Oscar Thompson entre de 1911 e 1917 de colocá-la em discussão. Desta maneira, ao buscar recolocar a educação rural paulista em pauta, Sud Menucci atentou para o fato de que era comum no Brasil, afirmar que nossas raízes são agrárias, que a essência econômica brasileira é rural. Contudo, de acordo com Menucci, foi após as campanhas ruralistas entre 1930 e 1934, que o país percebeu que a sustentação da zona rural é fundamental para a autonomia econômica e integridade territorial brasileira (MENUCCI, 1946, p. 107-108).

As exportações agrárias no início do século XX eram vitais para a economia brasileira. Isto que fez com a afirmação de que "o Brasil é um país essencialmente agrícola" não recebesse a atenção devida. Por sua importância econômica, esperava-se que o campo brasileiro fosse bem tratado, zelado, que o povo que ali habitava recebesse bons cuidados (MENUCCI, 1946, p. 108-111).

Porém, o que se via era um abandono social que se traduzia nas mazelas da educação rural, que como já nos é sabido, basicamente se resumia às escolas isoladas. Visando mudar esta situação, Sud Menucci propôs a Reforma do Ensino Rural paulista em 1932. Esta reforma estava pautada na especificidade da vida e do homem no campo, o que exigiria uma educação própria. De acordo com os pedagogos ruralistas, já era visível a muito tempo a incompatibilidade da escola do meio rural com a realidade que a cercava, pois não havia sintonia entre os objetivos escolares e o que os pais queriam que seus filhos aprendessem. Os colonos viam a escola rural como um corpo estranho que não os amparava, mas, os domesticava para conter perturbações sociais. Sud Menucci resumiu assim esta questão:

E - caso curioso por certo-quem tem razão é o colono, é o ignorante, o analfabeto. Quem não na tem é o homem culto, é o sábio, o especialista. Alicerçados os nossos educadores no preconceito norte-americano de que é sempre melhor possuir uma escola má do que não ter nenhuma, não entendem, não podem entender que na organização social a verdade é uma Deusa de múltiplas faces e aquilo que parece e é definitivo para um meio, pode bem não sê-lo para todos os demais (MENUCCI, 1946, p. 136).

Menucci nos colocava duas discussões, a primeira delas era a questão da influência norte-americana na educação brasileira tanto no meio rural quanto na cidade, que acontecia desde a primeira metade do século XX e que incentivava a educação enquanto medida compensatória, pois, não primava pela qualidade, apenas pela oferta. A segunda foi a elucidação dos princípios ruralistas, que se colocaram ao lado dos homens do campo, defendendo que a verdade do campo não coincidia com a verdade da cidade, nem a verdade americana afinava-se com a brasileira. Desta maneira, admitiam a existência de dois tipos de homens os citadinos e os rurícolas. Para Menucci,

nenhum homem do mundo, por mais bronco e tapado, deixou de se render à evidência dos benefícios que lhe pode prestar a instrução e a 
educação. Logo, se o campezino refuga o ensino que gratuitamente lhe oferece o Estado, se refoge de seus mestres e mentores é porque intuiu que esses mestres e ensino só lhe podem fazer mal. E na forma por que o estamos ministrando, esse ensino faz mal, sem nenhuma dúvida (MENUCCI, 1946, p. 138).

Assim, Sud Menucci não repudiava o valor da instrução e da educação, mas a forma como ela acontecia no campo, visto que, a repulsa do próprio campesino evidenciaria sua inadequação. Aqui a figura do mestre aparecia como ameaçadora, justamente por sua mentalidade calcada em valores urbanos.

A partir disto, uma das propostas da Reforma do Ensino Rural como a formação de novos educadores, com mentalidade coerente com a realidade e necessidades do campo, são evidenciadas. Para isso empreendiam o estabelecimento das Escolas Normais Rurais, o que dividiria o professorado em duas classes, a urbana e a rural, quiçá uma terceira classe, a dos professores litorâneos. As Escolas Normais Rurais se organizariam em três pontos de vista: o pedagógico, o sanitário e o higiênico, o que requereria três tipos de docentes, os professores propriamente ditos, os professores-médicos e os professores agrônomos (MENUCCI, 1946, p. 141-142). "Tais escolas têm de formar professores quase hostis à vida citadina, perenemente preocupados com a maior eficiência do campo e de tal modo que se constituam em líderes do núcleo em que vão servir" (MENUCCI, 1946, p. 142).

Fica evidente que uma das maiores preocupações dos ruralistas gravitava em torno do professor, que ao lidar diretamente com os alunos, deveria contribuir para a valorização do campo, e consequente fixação do homem nele. Esperava-se que os professores formados nas Escolas Normais Rurais abrissem mão de sua visão urbana e se tornassem representantes comunitários, ou seja, o que se desejava era formar professores identificados com a realidade e as formas de produzir do campo.

O ruralismo pedagógico não se limitou aos educadores. Alguns governantes aderiram a suas ideias, criando em seus territórios algumas escolas rurais, entretanto, atenderam parte das reivindicações ruralistas. Um dos fatores que contribuiu para isto foi a dificuldade de encontrar professores dispostos a lecionar no campo. Estes governos, mesmo contemplando parcialmente as premissas ruralistas, sofreram questionamentos acerca das medidas adotadas. Uma das maiores críticas foi dirigida ao curso de ruralismo, criado como anexo das escolas normais existentes e que supriria a falta das Escolas Normais Rurais que formariam professores aptos para a educação do homem que vive e trabalhos no campo (BEZERRA NETO, 2003, p. 15).

O curso de ruralismo conteria as seguintes disciplinas elencadas por Ary Lex,

a- Higiene Rural: alimentação; cuidados corporais; higiene doméstica; combate às moléstias;

b- Sociologia Rural: que estudaria os principais problemas criados pela vida social do campo, a fim de que os professores pudessem interpretá-los e cooperar na sua solução;

c- Educação Rural: ensino da leitura e da linguagem no meio rural; educação física; jogos e todos os ensinos através de centros de interesse rurais;

d- Atividades Rurais: visando a estimular nos mestres a simpatia pelo campo, para que depois eles transmitissem aos alunos (LEX, 1973, p. 250). 
Este curso atenderia grande parte das necessidades daqueles que viviam no meio rural, pois os pouparia do deslocamento para as cidades e da contaminação do discurso urbanista dos professores que vinham ensinar no campo. Além disso, poderia permitir uma compreensão mais ampla da realidade do meio rural, mostrando suas múltiplas faces, como a precariedade da formação educacional, a pobreza das moradias e ausência de atrativos culturais que oferecessem diversão aos jovens (BEZERRA NETO, 2003, p. 16).

Talvez- por essa razão- se atribuísse à educação um papel que ela jamais poderia ter, que seria o de criar mecanismos de fixação do homem em um habitat considerado hostil e sem nenhum atrativo para o homem civilizado da cidade. Por outro lado, era necessário compreender que, se o campo não tinha atrativos para seus habitantes, ou se o meio urbano atraía e encantava o trabalhador rural, caberia à sociedade, como um todo, desenvolver mecanismos de retenção do trabalhador no ambiente que este julgasse mais adequado. Isso poderia se dar através de investimentos realizados em infra- estrutura, lazer e condições de habitabilidade, bem como com a possibilidade de emprego e geração de renda que o setor pudesse oferecer, visto que são as condições de vida, de empregabilidade e de salários que atraem o trabalhador e não apenas a facilidade de acesso ao comércio, posto de saúde, escola e lazer que a cidade poderia oferecer (BEZERRA NETO, 2003, p. 16-17).

Ou seja, os ruralistas acreditavam que uma pedagogia voltada para a realidade dos homens que habitavam o meio rural seria suficiente para fixá-los naquele ambiente, que não apresentava atrativos tanto para aqueles que nele viviam quanto para os habitantes das cidades. Entretanto, a discussão realizada por Bezerra Neto nos alerta que a educação nunca teve e não terá esta capacidade, o que o fará é mais do que a oferta de lazer, educação, cultura e tantas outras políticas públicas, mas, as condições de vida, de trabalho, empregabilidade e salários, pois é com seus salários que os trabalhadores adquirem os bens necessários à sobrevivência, podendo assim, fixar-se em qualquer ambiente.

Portanto, o que colaboraria para a fixação do homem no campo não seriam medidas educacionais, mas ações que incidissem na melhoria das condições de vida do homem do campo, que os libertasse das técnicas de cultivo arcaicas que esgotam o trabalhador rural e não colaboram para o aumento da produtividade e consequente melhora nos ganhos financeiros.

Imbuídos desta mentalidade, de que a educação fixaria o homem do campo à terra, os cursos de ruralismo, a pouco mencionados, foram um marco para esta corrente uma vez que,

Somente a partir dessas tentativas de investimentos técnicos e financeiros voltados para a educação do campo, é que podemos falar efetivamente do ruralismo como um movimento pedagógico que se deu não apenas no Brasil, mas em várias partes do mundo. Intelectuais, considerados nacionalistas trataram de difundi-lo (BEZERRA NETO, 2003, p.17).

Não podemos compreender o ruralismo pedagógico sem entender as ideias nacionalistas que permeavam à época, aquele contexto fez brotar muitas propostas pedagógicas com várias facetas nacionalistas. Havia um embate que envolvia pensadores como Anísio Teixeira que defendia a industrialização e outros como o já mencionado Sud Menucci, Carneiro Leão e Alberto Torres que vinham em defesa da ruralização do país. Contudo, todos eles guardavam em comum a defesa da língua portuguesa e do fortalecimento da nação e do ensino (BEZERRA NETO, 2003, p. 20). 
Assim, em um período em que o Brasil já sentia a influência norte-americana em sua educação, pensadores, mesmo com visões econômicas antagônicas se esforçaram na disseminação de uma mentalidade nacionalista, defendendo nossa língua, nação e uma educação identificada com elas. Porém, o debate ruralista foi se esfriando com o passar dos anos, e consequentemente diminuiu-se a atenção à educação no campo.

Andrade e Di Pierro (2004, p. 5-6) elucidam que,

Entre 1945 e 1960 foram implementadas campanhas de alfabetização e programas de educação popular destinados aos jovens e adultos, a maioria dos quais assumiu caráter assistencialista, por considerar a população do campo inculta, atrasada e desajustada. Adotando uma perspectiva diversa, alguns dos movimentos de educação popular que se desenvolveram nesse período comportaram iniciativas especialmente voltadas à população rural, como as escolas radiofônicas organizado pelo Movimento de Educação de Base, que recebeu forte influência da pedagogia libertadora formulada por Paulo Freire (ANDRADE E DI PIERRO, 2004, p. 5-6).

Desta maneira, as autoras nos mostraram que se na década de 1930 houve um movimento em favor de uma educação própria para o campo, de meados da década de 1940 à década de 1960, ela foi marcada por iniciativas assistencialistas que viam a população rural de modo pejorativo e eram marcadas por um ecletismo metodológico, amparado pela teoria de Paulo Freire. Estas iniciativas incidiam, sobretudo, sobre os jovens e adultos analfabetos do meio rural, evidenciando, novamente os altos índices de analfabetismo naquele meio.

A industrialização e investimentos em infraestrutura urbana, a partir das décadas de 1950 e 1960, fizeram com que muitos trabalhadores analfabetos saíssem do campo e fossem para a cidade, o que prova que a leitura não era necessária para o ingresso neste novo mercado de trabalho, derrubando, o discurso dos ruralistas de que a má formação escolar colaborava para a expulsão do homem do campo. O processo de modernização conservadora do campo brasileiro, a partir da década de 1970, foi outra condição que seguramente colaborou para o avanço do êxodo rural (BEZERRA NETO, 2003, p. 54).

Assim, pudemos perceber que desde os anos 1890 a educação não tem sido prioridade nacional, tanto no campo quanto na cidade. Devido ao fato da economia brasileira ser predominantemente agrária, esperava-se que o campo apresentasse boas condições de vida e acesso à bens sociais como a educação, porém, o que vimos foi uma diferenciação histórica em relação à educação oferecida na cidade. Na década de 1930 os educadores ruralistas buscaram alertar a sociedade brasileira para esta situação, propondo mudanças que originassem uma educação voltada para o homem do campo e seus fazeres, contudo, os rumos econômicos do país privilegiaram a industrialização e o meio urbano, colocando a educação escolar no campo em um segundo plano nos investimentos governamentais, o que certamente colaborou para as condições materiais e humanas desfavoráveis das escolas no campo, denunciadas no início deste trabalho.

\section{Referências}

ANDRADE, Márcia Regina; DI PIERRO, Maria Clara. Programa Nacional de Educação na Reforma Agrária em perspectiva: dados básicos para uma avaliação. São Paulo: Ação Educativa, 2004. 82 p. Disponível em: <http://www.bdae.org.br/dspace/bitstream/123456789/2311/1/ensaio_introdutoriopronera. pdf> Acesso em: 29 de maio de 2012. 
ANTUNHA, Heládio César Gonçalves. Instrução Pública no Estado de São Paulo: A Reforma de 1920. São Paulo: Universidade de São Paulo, 1976. 297p.

BEZERRA NETO, Luiz. Avanços e retrocessos da educação rural no Brasil. 2003. 221p. Tese (Doutorado em Educação)- Faculdade de Educação, Universidade Estadual de Campinas, Campinas, 2003.

CARVALHO, José Murilo de. Mandonismo, Coronelismo, Clientelismo: uma discussão. Dados, vol. 40, n. 2. Rio de Janeiro, 1997. s.p. Disponível em: <http://www.scielo.br/scielo.php?pid=S0011-52581997000200003\&script=sci_arttext> Acesso em: 11 de dezembro de 2012.

DEMARTINI, Zeila de Brito Fabri. Cidadãos Analphabetos: propostas e realidade do ensino rural em São Paulo na $1^{\text {a }}$ República. Caderno de Pesquisas, n. 71. São Paulo: 1989. pp. 5-19

GRAMSCI, Antonio. A organização da Escola e da Cultura in: Os Intelectuais e a Organização da Cultura. Tradução: Carlos Nelson Coutinho. Rio de Janeiro: Civilização Brasileira, 1968. pp. 117- 139. Coleção Perspectivas do homem, v. 48, Série Filosofia.

KOLLING, Edgar Jorge; NÉRY, Israel José; MOLINA, Mônica Castagna. Por uma educação básica do campo. Brasília: Fundação Universidade de Brasília, 1999. Vol. I. 95p.

LEX, Ary. Biologia Educacional: para uso das escolas normais, institutos de educação e faculdades de filosofia. 14 ${ }^{\mathrm{a}}$ ed. São Paulo: Companhia Editora Nacional, 1973. 277p.

MENUCCI, Sud. Discursos e conferências ruralistas. São Paulo: s. ed., 1946. 223p.

SAVIANI, Dermeval. História das Ideias Pedagógicas no Brasil. 2ªed. Campinas: Autores Associados, 2008. 474p.

SOUZA, Rosa Fátima de. Alicerces da pátria: história da escola primária no Estado de São Paulo (1890- 1976). Campinas, SP: Mercado das Letras, 2009. 407p.

Notas:

${ }^{1}$ Mestre em Educação pelo Departamento de Pós- Graduação em Educação da Universidade Federal de São Carlos- UFSCar e pesquisadora no Grupo de Estudos e Pesquisas sobre Educação do Campo- GEPEC/ UFSCar Email: jdbassoufscar@hotmail.com

${ }^{2}$ Professor adjunto do Departamento de Educação da Universidade Federal de São Carlos - UFSCar e coordenador do Grupo de Estudos e Pesquisas sobre Educação do Campo - GEPEC/UFSCar. Email: lbezerra@ufscar.br

${ }^{3}$ É importante destacarmos que o termo educação popular aqui não tem o mesmo significado utilizado por Marx na Crítica do Programa de Gotha, em que representa um rebaixamento da educação. No texto de Rosa Fátima de Souza, em que nos embasamos, o termo educação popular ganha o sentido de educação para todos, no caso ela buscava diminuir os índices de analfabetismo.

Recebido em abril-13

Aprovado em maio-13 